\title{
Cochinchinochloa (Gramineae: Bambusoideae-Bambusineae), a new bamboo genus endemic to Braian mountain, southern Vietnam
}

\author{
H.N. Nguyen ${ }^{1 *}$, V.T. $\operatorname{Tran}^{1 *}$, T.T. Hoang ${ }^{1}$
}

\section{Key words}

Bambusinae

Bambusoideae

Cochinchinochloa

C. braiana

new genus

taxonomy

\begin{abstract}
A clambering bamboo endemic to Braian mountain, southern Vietnam represents a new monotypic endemic genus, Cochinchinochloa H.N.Nguyen \& V.T.Tran (Gramineae: Bambusoideae-Bambusinae), which is described and illustrated. Its culm nodes and the nodes of leafy branches exhibit a thick swollen patella, and in the reproductive state this taxon bears pseudospikelets having two perfect florets, with an elongated rachilla internode between the perfect florets, a rachilla extension bearing an imperfect floret at maturity, a narrowly 2-keeled palea with a distinct abaxial groove, three lodicules, six stamens, free filaments, a glabrous ovary with a long style and three stigmas, and an oblong caryopsis with a relatively thin pericarp.
\end{abstract}

Published on 7 June 2013

\section{INTRODUCTION}

Asian clambering or scrambling genera in the tribe Bambuseae Kunth ex Nees, which are characterized by each node giving rise to several branches, with one becoming longer and dominant, and with a basic caryopsis have now been clearly demarcated into groups. The first group is placed in the subtribe Bambusinae J.Presl, which is characterized by iterauctant inflorescences. This group contains four genera which are currently recognized as distinct: a) Mac/urochloa K.M.Wong and b) Soejatmia K.M.Wong from the Malay Peninsula (Wong 1993); c) Neololeba Widjaja from the Philippines, central and eastern Indonesian island, New Guinea and Queensland (Widjaja 1997); d) Mullerochloa K.M.Wong from north-east Australia (Wong 2005). The second group is placed in the subtribe Hickelinae Camus, which is characterized by having semelauctant inflorescences. One genus is currently recognized in this group: e) Temburongia S.Dransf. \& K.M.Wong from Brunei (Dransfield \& Wong 1996). Investigating essentially these aspects for taxa (Maclurochloa, Soejatmia, Neololeba, Mullerochloa) previously classified in Bambusa, Wong (1993, 2005) and Widjaja (1997) found many additional characters distinguishing one or more of these genera from the type alliance of Bambusa s.s. (Table 1) Maclurochloa differs from Bambusa in having only one or two perfect flowers in the spikelet, which also has 3-5 transitional (empty) glumes, of which the upper ones are as large as the lemma, and an ovary summit is not thickened; additionally, the primary-branch bud prophyll has free margins in Maclurochloa, but in Bambusa has fused margins. Soejatmia has rudimentary flowers below the perfect flowers and a distinctly bifid palea apex with hooked tips, along with other points of difference from Bambusa s.s. Mullerochloa is distinguished from Bambusa by its strongly flattened rachilla internodes, four stamens and filaments fused into a tube. Neololeba can be distinguished from Bambusa by its simple branching system and a range of floral characteristics including pseudospikelet shape, the length of the

\footnotetext{
Forest Science Institute of Vietnam, Dong Ngac, Tu Liem, Hanoi, Vietnam; corresponding authors e-mail:nhnghia@netnam.vn; tvtien117@yahoo.com.
}

rachilla internodes, the absence of lodicules, and ovary shape, and it also lacks the basal branches and robust, thick-walled culms of Bambusa. In contrast, Temburongia is distinguished from Greslania Balansa by its split prophyll at the base of the spikelet and the structure of each spikelet-bearing branch along the main inflorescence axis. Therefore, better morphological studies of the flowers and fruits, plant architecture and habit of these aberrant taxa may assist in defining groups.

During our investigation of the bamboos from Braian mountain, Di Linh District, Lam Dong Province, southern Vietnam in January 2011, the authors found several populations of bamboo widespread and abundant through degraded natural forest in valleys and mountain gorges. Specimens of rhizomes, branches, culm leaves, and flowering branches were collected. All collected specimens were dissected and studied. We confirmed the presence of sympodial rhizomes in this bamboo with clambering culms, and the branch complement at each node bearing several branches with the middle one dominant; the pseudospikelets were clustered at distal nodes, each having two perfect florets and one imperfect floret, palea 2-keeled. The form and structure of rhizome, branches and inflorescences in the collected specimens are basically similar to that of the first four genera discussed above. Otherwise, the glabrous ovary with the long style is typical for Mullerochloa and also found in the subtribe Melocanninae Trin. However, the pseudospikelet of Mullerochloa is characterized by having 4-9 flowers, the rachilla internodes are not truly elongate, and there are 4 stamens with fused filaments (Wong 2005). The branch complement of the subtribe Melocanninae is typical a cluster of subequal-sized axes, and the palea is unkeeled.

Furthermore, in our specimens the culm nodes develop a circumaxial ridge or patella; the inflorescences are born terminally on leafy branches; in mature pseudospikelets the elongated rachilla internode bears a fertile floret which easily disarticulates at maturity; a rachilla extension is present bearing an imperfect floret elongate at maturity; and the caryopsis is oblong with a relatively thin pericarp and long, comparable to the inflorescence and spikelet structure of Temburongia. But Temburongia has semelauctant or determinate inflorescences and the 


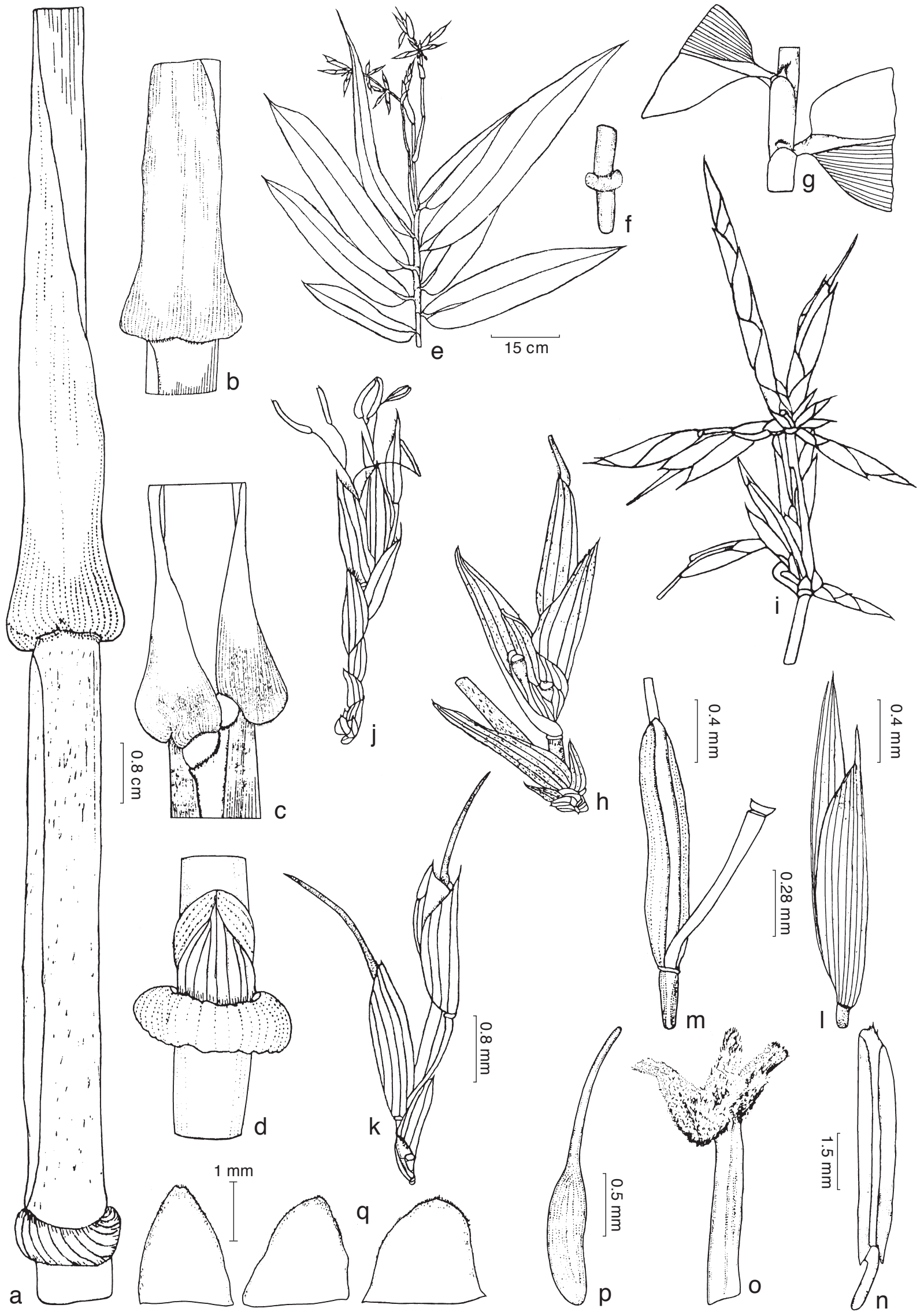

Fig. 1 Cochinchinochloa braiana H.N.Nguyen \& V.T.Tran. a. Culm leaf; b. dorsal view of culm leaf; c. ventral view of culm leaf with auricles; d. section of internode with thick swollen patella and bud; e. branchlets with leaves and flowering branch; f. section of internode of leafy branch with swollen patella; g. section of leafy branch; h, i. section of flowering branches; j. pseudospikelet; k. pseudospikelet with two florets; I. floret; m. 2-keeled, grooved palea; n. stamen; o. stigmas; p. caryopsis; q. lodicules (drawn from holotype). 


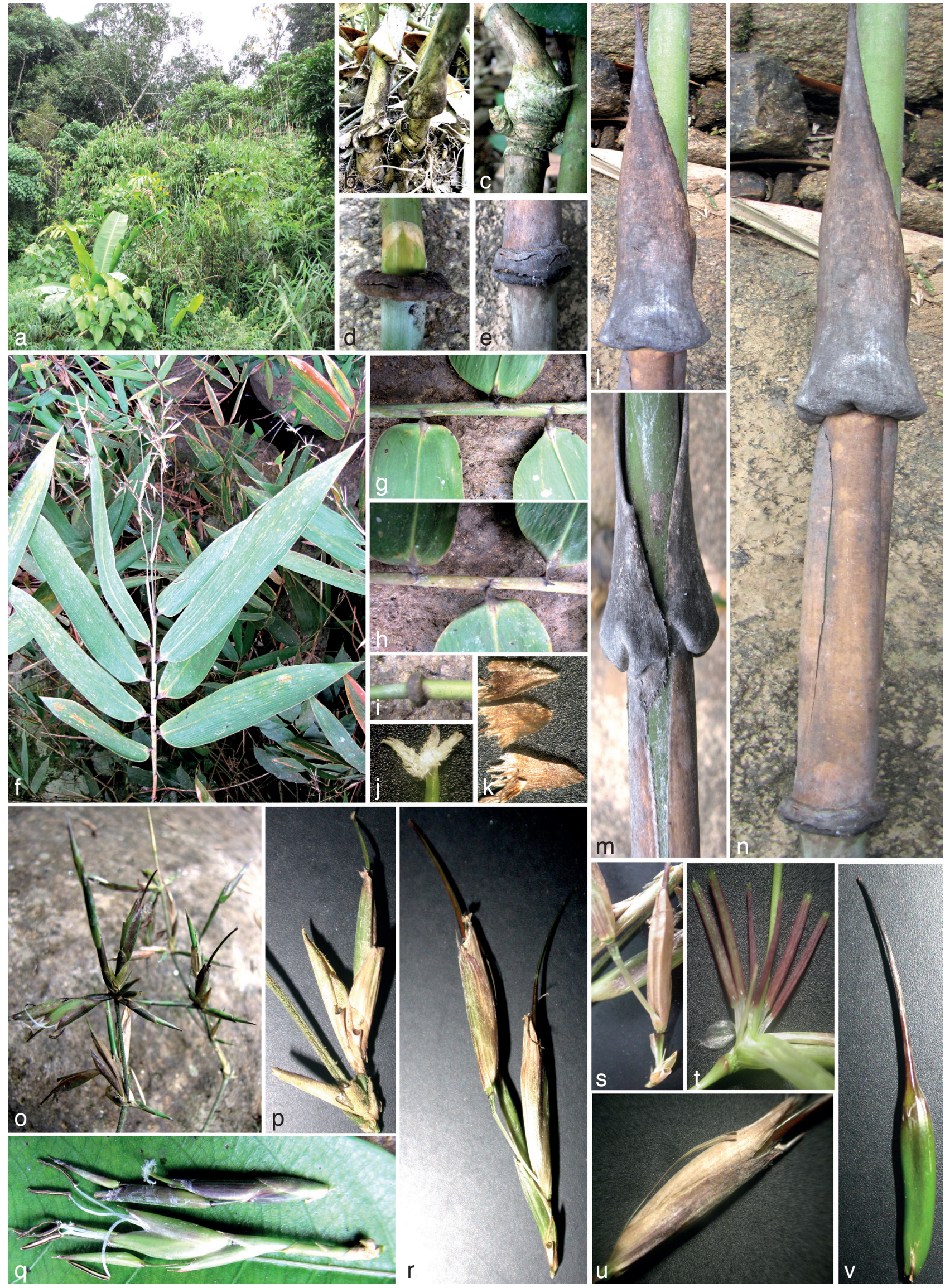

Fig. 2 Cochinchinochloa braiana H.N.Nguyen \& V.T.Tran. a. Habitat; b. rhizome with short necks; c. branches with middle one dominant; d. internode with thick swollen patella and bud; e. base of culm leaf; f. leafy flowering branch; g. section of leafy branch with under leaves surface; $h$. section of leafy branch with upper leaves surface; i. section of internode of leafy branch with thick swollen patella; j. stigmas; k. lodicules; I. ventral view of culm leaf with auricles; m. dorsal view of culm leaf; n. culm leaf; o, p. section of flowering branches; q, r. pseudospikelets with two florets; s. 2-keeled, grooved palea; t. lodicules and stamens; u. floret; v. caryopsis. - Photos by Tran Van Tien from the type locality. 


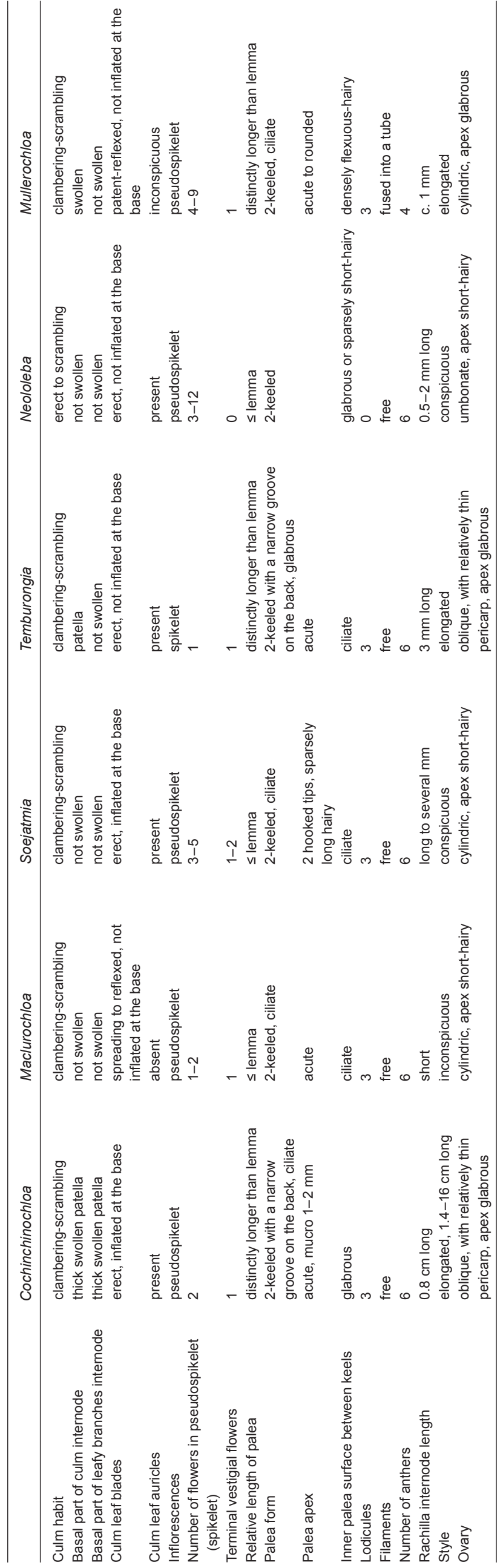

spikelets develop individually. Because this combination of inflorescence structure along with the other features described here is not found in any other described bamboo genus, we propose to recognize this taxon as a new monotypic genus named Cochinchinochloa, with C. braiana as the type species.

\section{MATERIAL AND METHODS}

Living plants of this species were found in Braian mountain, Di Linh District, Lam Dong Province, southern Vietnam in January 2011. Voucher specimens were deposited in VAFS (Herbarium of Vietnam Academy of Forestry Science - formerly Forest Science Institute of Vietnam). Fresh flowers were examined under an Olympus SX-41 light microscope and colour photographs were made using a Canon Power Shot SX10IS; line drawings and descriptions were made from fresh material. Presumably related genera were used for critical comparison.

\section{RESULTS}

Cochinchinochloa H.N.Nguyen \& V.T.Tran, gen. nov. — Fig. 1

Type species. Cochinchinochloa braiana H.N.Nguyen \& V.T.Tran.

Etymology. The generic epithet refers to the Cochinchine area (southern Vietnam, which includes Braian mountain, Lamdong Province where the species is located), and -chloa: grass.

Densely tufted with rhizomes short-necked, pachymorph. Culms and branches scrambling or hanging over nearby vegetation or trees; culms of medium size, with relatively thin walls, nodes with a thick swollen patella. Branches several with the middle one dominant, elongating. Culm leaves usually purplish when young; the blade erect and inflated at the base, tardily deciduous; auricles present. Nodes of leafy branches with a thick swollen patella; leaf sheaths dense white cilia, auricles present. Inflorescence terminating leafy branches, indeterminate; each pseudospikelet subtended by a prophyllate bud and consisting of 1-3 transitional glumes, apex acute mucronate, margins shortly white-hispid, abaxial surface white cilia; two perfect florets; the rachilla internode between the perfect florets elongate; and a rachilla extension bearing an imperfect floret elongate at maturity; perfect floret consisting of lemma and palea; lemma oblong-lanceolate, shorter than the palea, apex acute, mucronate, convolute and uncovered palea, margins dense cilia; palea 2-keeled with a narrow groove on the back, apex obtuse, margins dense cilia; lodicules 3 , apex obtuse, dense ciliate; stamens 6 , filaments free; glabrous ovary with long style; stigmas 3 , plumose; caryopsis oblong with relatively thin pericarp.

Note - This remarkable genus is distinctive based on the presence of a thick swollen patella at the culm nodes and nodes of leafy branches, pseudospikelets having two perfect florets, the rachilla internode between the perfect florets elongated, a rachilla extension bearing an imperfect floret at maturity, a narrowly 2-keeled palea with an abaxial groove, three lodicules, six stamens, free filaments, a glabrous ovary with a long style and three stigmas, and an oblong caryopsis with relatively thin pericarp.

Cochinchinochloa braiana H.N.Nguyen \& V.T.Tran, sp. nov.

$$
\text { - Fig. 1, } 2
$$

Typus. V.T. Tran, T.T. Hoang \& H.N. Nguyen 312012 (holo VAFS; iso (VNMN-Vietnam National Museum of Nature)), Vietnam, Lamdong Province, Di Linh District, Braian mountain, Suoi Lanh, elevation 1130 m asl, N11 ${ }^{\circ} 26^{\prime} 44^{\prime \prime}$ E108 $04^{\prime} 07^{\prime \prime}, 3$ Jan. 2011.

Etymology. The specific epithet refers to the type locality, Braian mountain, Di Linh District, Lamdong Province, Vietnam. 
Culms and branches scrambling or hanging over nearby vegetation or trees, 8-15 m tall; internodes $60-80 \mathrm{~cm}$ long and $2-3.5 \mathrm{~cm}$ diam, when young sparsely covered with appressed white hairs; culm walls $2-3 \mathrm{~mm}$ thick; nodes with a thick swollen patella. Branches several with the middle one dominant, elongating. Culm leaves purplish green, when young covered with densely appressed white hairs on the abaxial surface; 20-23 $\mathrm{cm}$ long and 9-12 cm wide at the base, $6-8 \mathrm{~cm}$ wide at the top, the junction with the blade more or less horizontal, margins bearing dense white-brown hairs; blade tardily deciduous, erect, inflated at the base and base purple-brown, $20-25$ by $12-15$ $\mathrm{cm}$, abaxial dense white hairs, margins densely ciliate at the base; auricle triangle shaped, $1.5-2.5$ by $0.6-0.8 \mathrm{~cm}$, margins bearing dense purple-brown bristles, c. $0.4 \mathrm{~cm}$ long; ligule very short, entire. Leafy branches $40-60 \mathrm{~cm}$, nodes with a thick swollen patella, bearing 5-8 leaves; blades oblong-obovate, base broadly rounded, glabrous, $30-35$ by $6.5-7.0 \mathrm{~cm}$, veins in $10-12$ pairs; sheaths bearing auricles c. 0.2 by c. $0.1 \mathrm{~cm}$ with dense bristles 4-6 mm long; inner ligule a low rim, c. $1 \mathrm{~mm}$; pseudopetiole c. 0.2 by c. $0.2 \mathrm{~mm}$. Inflorescences terminating leafy branches, indeterminate; pseudospikelets typically 2-3 $\mathrm{cm}$ when young and $4-5 \mathrm{~cm}$ at maturity, each subtended by a prophyllate bud and consisting of 1-3 transitional glumes, having two perfect florets and a vestigial terminal flower. Rachilla internode below the lower fertile floret does not elongate at maturity, c. $0.2 \mathrm{~cm}$; rachilla internode between perfect floret elongate, c. $0.8 \mathrm{~cm}$; and a rachilla extension bearing an imperfect floret at maturity, c. $1 \mathrm{~cm}$. Perfect florets consisting of lemma and palea; lemmas oblong-lanceolate, $1.1-1.3$ by $0.3-0.4 \mathrm{~cm}$, veins 9-11, apex acute, mucro 1-2 mm long, shorter than the palea, margins bearing dense white cilia at the apex; palea 2-keeled with a narrow groove on the back, $1.6-1.8$ by $4-4.5 \mathrm{~mm}$, the apex acuminate, mucro 1-2 mm long, margins bearing dense white cilia at the top; lodicules 3 , obovate, $1.7-2$ by c. $1 \mathrm{~mm}$, margins ciliate; stamens 6 , filaments free, $4-5$ by $0.4-0.5 \mathrm{~mm}$, apiculate with short tips; ovary glabrous with a long style and stigmas 3; caryopsis green when fresh, oblique, with a relatively thin pericarp, $1.2-1.5 \mathrm{~cm}$ long, protruding from the palea.

Distribution \& Habitat - This bamboo grows in the degraded natural forest in valleys, but is also common along rivers or valleys, between 1000 and $1200 \mathrm{~m}$ asl, southern Vietnam.

Phenology - The plants were flowering between September and February. New shoots developed in June-August.

Local uses - This species is of considerable importance to the local people. Its culms are used for making handicrafts and household tools.

Acknowledgements The authors would like to express their sincere thanks to Prof. dr. Lynn G. Clark for her patient evaluation of the manuscript. The authors also wish to thank the anonymous reviewers for constructive comments and suggestions. We thank also Prof. dr. Khoon Meng Wong for his kind help in references.

\section{REFERENCES}

Dransfield S, Wong KM. 1996. Temburongia, a new genus of bamboo (Gramineae: Bambusoideae) from Brunei. Sandakania 7: 49-58.

Wong KM. 1993. Four new genera of bamboos (Gramineae: Bambusoideae) from Malesia. Kew Bulletin 48: 517-532.

Wong KM. 2005. Mullerochloa, a new genus of Bamboo (Poaceae: Bambusoideae) from north-east Australia and notes on the circumscription of Bambusa. Blumea 50: 425-441.

Widjaja EA. 1997. New taxa in Indonesian bamboos. Reinwardtia 11: 57-152. 